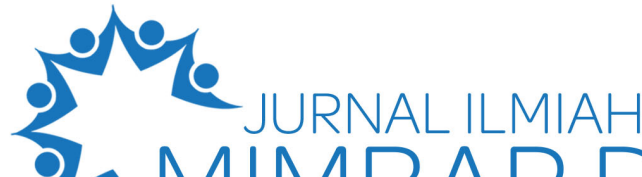 aMIMBAR DEMOKRASI

Vol. 21 No. 1 Tahun 2021 | Hal. $34-41$

\section{Strategi penguatan kewarganegaraan ekologis pada Kelompok Tani Berdikari di Kota Banjarbaru}

\author{
Reja Fahlevi a, 1*, Alamanik Suryo Kuncoro b, 2 . \\ ab Prodi Pendidikan Pancasila dan Kewarganegaraan, Universitas Lambung Mangkurat Banjarmasin, Indonesia \\ ${ }^{1}$ reja.fahlevi@ulm.ac.id*; ${ }^{2}$ almanikuncoro@gmail.com. \\ *Korespondensi penulis
}

\begin{tabular}{l}
\hline Informasi artikel \\
\hline Diterima: \\
04-08-2021 \\
Disetujui: \\
30-09-2021
\end{tabular}

Kata kunci:

Strategi penguatan

Kewarganegaraanekologis

Kelompok tani

\begin{abstract}
ABSTRAK
Rendahnya kesadaran warga negara untuk memelihara dan menjaga lingkungan, mengakibatkan lingkungan menjadi tidak terawat dan rusak. Sehingga diperlukan strategi penguatan kewarganegaraan ekologis sebagai upaya agar lingkungan tetap dirawat dan diperhatikan. Penelitian ini bertujuan ini untuk menggali strategistrategi yang dilakukan dalam Bertani dengan konsep mencintai alam dan berkelanjutan. Penelitian ini menggunakan pendekatan kualitatif dengan metode studi kasus yang menyelidiki secara teliti dan detail mengenai sebuah program, peristiwa, maupun sebuah aktivitas. Hasil Penelitian menunjukan bahwa strategi penguatan kewarganegaraan ekologis yang sudah dilakukan oleh Kelompok Tani Berdikari melalui implementasi konsep aman, selamat, dan sehat dalam mengolah hasil taninya serta menjaga lingkungan sekitar, dan melakukan kerja sama dengan stakebolder, seperti dinas pertanian. Hambatan-hambatan yang ditemui para petani yang tergabung di dalam Kelompok Tani Berdikari dalam mengimplementasikan strategi ini dari faktor alam dan ekonomi.
\end{abstract}

\section{Received:}

04-08-2021

Accepted:

30-09-2021

\section{Keywords:}

Strengthen strategy

Ecologival Citizenship

Farmers Group

\begin{abstract}
Strategies for Strengthening Ecological Citizenship in Berdikari Farmer Groups in the city of Banjarbaru. The low awareness of citizens to care for and protect the environment has resulted in the environment being neglected and damaged. So that a strategy to strengthen ecological citizenship is needed in an effort to keep the environment cared for and cared for. This study aims to explore strategies implemented in farming with the concept of loving nature and sustainability. This study uses a qualitative approach with a case study method that investigates carefully and in detail about a program, event, or activity. The results showed that the strategy of strengthening ecological citizenship that had been carried out by the Berdikari Farmer Group was through the implementation of the concept of safe, secure, and healthy in processing their crops and protecting the surrounding environment, and collaborating with stakeholders, such as the agriculture agency. The obstacles encountered by farmers who are members of Berdikari Farmer Group in implementing this strategy are based on natural and economic factors.
\end{abstract}

\section{$\overline{\text { Copyright (C) } 2021 \text { (Reja Fahlevi \& Alamanik Suryo Kuncoro). All Rights Reserved }}$}

How to Cite: Fahlevi, R., \& Kuncoro, A.S. (2021). Strategi penguatan kewarganegaraan ekologis pada Kelompok Tani Berdikari di Kota Banjarbaru. Jurnal Ilmiah Mimbar Demokrasi,21(1), 35-41. DOI: http://doi.org/10.21009/jimd.v21i1.22295

This work is licensed under a Creative Commons Attribution-ShareAlike 4.0 International License. Allows readers to read, download, copy, distribute, print, search, or link to the full texts of its articles and allow readers to use them for any other lawful purpose. The author (s) bolds the copyright.

\section{Pendahuluan}

Isu kerusakan lingkungan hari ini merupakan isu global. Hampir setiap negaranegara di dunia menjadikan persoalan lingkungan sebagai prioritas dalam mengambil kebijakan. Sebagai salah usaha untuk memberikan perlindungan lingkungan dan membantu untuk memastikan bahwa kehidupan bagi generasi 
mendatang akan terhindar dari kerusakan lingkungan yang lebih parah. (Gusmadi \& Samsuri, 2020, hal. 381).

Partisipasi dan tanggung jawab untuk sama-sama menjaga lingkungan merupakan tanggung jawab semua lapisan masyarakat. Baik itu, pemerintah selaku pemangku kebijakan, organsisasi-organisasi kemasyarakatan, terlebih yang paling penting yakni semua lapisan masyarakat atau yang sering disebut sebagai warga negara (citizen). Warga negara merupakan salah satu unsur pembentuk negara yang memilki hak dan kewajiban. Salah satu wujud hak dan kewajiban sebagai warga negara yakni pelestarian alam dan lingkungan. (Prasetyo \& Dasim, 2016, hal. 178).

Pelestarian alam dan lingkungan menjadi hal yang sangat penting karena untuk memenuhi kebutuhannya dan kelangsungan hidupnya secara berkelanjutan warga negara sangat bergantung kepada alam. (Mariyani, 2017, hal. 10; Jannah, 2018, hal. 15). Implementasi usaha pelestarian lingkungan tidak hanya dioptimalisasikan pada sektor pembelajaran yang ada di pendidikan formal saja. Namun, harus lebih masif dilakukan pada ranah masyarakat. Khususnya mengoptimalkan peran kelompok-kelompok sosial atau organisasi kemasyarakatan (NGO) yang ada di tengah-tengah masyarakat. Dalam kajian Syahri (2013) bahwa kegiatan partisipasi warga negara dapat digerakkan dengan penguatan organisasi-organisasi relawan pecinta lingkungan hidup. Partisipasi tersebut bisa dilakukan dengan memberikan pembekalan dimensi pengetahuan, keterampilan dan nilai karakter peduli lingkungan sehingga tercapainya kepekaan melindungi lingkungan hidup. (Gusmadi, 2018, hal. 107).

$$
\text { Dalam konsep pendidikan }
$$

kewarganegaraan sebetulnya telah mengenal konsep pendidikan lingkungan dengan nama kewarganeraan lingkungan (ecological citizenship), namun saat ini pendidikan kewarganegaraan Indonesia masih terbatas sektor pendidikan formal saja atau pendidikan sekolah. Padahal dalam realitas yang terjadi bahwa kerusakan lingkungan banyak dilakukan oleh masyarakat dewasa yang sudah tidak lagi tersentuh dalam pendidikan formal. Dalam hal ini tentu warga negara tidak hanya dibatasi oleh jenjang pendidikan formal semata melainkan juga dalam lingkup yang luas yakni sosio kultural, seperti Civic Coorporate, sosial bidaya masyarakat Indonesia dan Comunity civic education pendidikan kewarganegaraan Indonesia dapat bergerak menuju kontinum yang lebih luas yakni
Pendidikan warga negara kemasyarakatan. (Mustikarini \& Feriandi, 2020, hal. 60).

Hal di atas tentunya sejalan dengan konsep pendidikan kewarganegaraan di masyarakat yang dikenalkan oleh Isin \& Turner, ia mengatakan bahwa pendidikan kewarganegaraan masyarakat merupakan suatu gagasan baru yang diupayakan untuk membentuk kesadaran warga negara dalam hal ini kesadaran warga masyarakat di dalam kelompok atau organisasi sosial agar selalu terlibat dalam menjaga kelestarian hidup. (Isin \& Turner, 2002).

Kewarganegaran ekologis hakikatnya berisi tentang kesadaran akan pemahaman tentang isu-isu ekologi hak-hak, kewajiban, tanggung jawab serta partisipasi warga negara dalam menjaga lingkungan sekitarnya dan tindakan untuk mempromosikan interaksi manusia dan lingkungan yang positif secara berkelanjutan (Berkowitz, 2005, hal. 227).

Peran pendidikan kewarganegaraan di masyarakat memiliki posisi yang sangat strategis dalam rangka proses memberikan stimulus pengetahuan serta pembentukan karakter masyarakat. Serta yang lebih penting agar pendidikan kewarganegaraan berbasis kewarganegaraan ekologis hendaknya selalu mefokuskan diri pada lingkungan sekitar. (Fahlevi, et al, 2020, hal. 69). Terlebih dengan posisi non-government organizations (NGO) atau lembaga swadaya masyarakat.

Selama ini, usaha perbaikan dan pemeliharan lingkungan yang masif dilakukan oleh pemerintah hanya melalui pembentukan peraturan regulasi perundang-undangan mengenai lingkungan. Bahkan peraturan perlindungan lingkungan tersebut dimasukan oleh beberapa negara, dalam hukum dasarnya atau yang dikenal dengan istilah konstitusi. Maka dikenalah dengan istilah green constitusion (Faiz, 2016).

Maka dari itu jika pelindungan lingkungan hanya melalui peraturan perundangundangan bisa dikatakan belum efektif. Karena hanya menimbulkan kesadaran sementara, yang dikarenakan hanya dari ketakutan akan sangsi dan hukuman yang diberikan oleh pemerintah jika merusak tatanan lingkungan (Dobson, 2017, hal. 276). Sehingga ketika nanti ditemukan kesempatan dan peluang untuk melanggar peraturan tersebut, maka masyarakatt bisa saja melanggar peraturan itu. Tentu hal ini terjadi karena disebabkan tidak adanya kesadaran dari masyarakat (Dobson, 2017, hal. 285) 


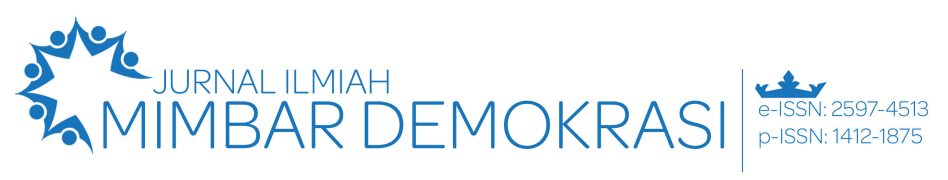

Vol. 21 No. 1 Tahun 2021 | Hal. 35 - 41

Pola penelitian terkait tema ini sebetulnya sudah cukup banyak dilakukan. Berdasarkan penelitian dari Sari, et al (2020, hal. 105) bahwa bentuk pelestarian lingkungan oleh Kampung Gambiran sebagai Kampung Hijau di Kota Yogyakarta melalui berbagai programprogtam pengelolaan sungai Gajah Wong, tanam pohon, pengelolaan sampah mandiri, Instalasi Pengolahan Air Limbah (IPAL) komunal, Ruang Terbuka Hijau (RTH), taman krida dan taman lintas budaya, perpustakaan dan taman $W i F i$, serta penggunaan energi alternatif.

Berdasarkan penelitian lain yang dilakukan oleh Nurmayanti (2017, hal. 97) tentang strategi Yayasan Mangrove Center Tuban dalam menguatkan kewarganegaraan ekologis mengidentifikasi bahwa strategi pengembangan kewarganegaraan ekologis dalam masyarakat Tuban ialah terjalinnya hubungan baik antara manusia dan alam melalui kegiatan konservasi, kehidupan ekonomi masyarakat yang berwawasan lingkungan dan masyarakat memiliki kepedulian serta kesadaran terhadap hak dan kewajibannya dalam menjaga kelestarian lingkungan.

Kelompok Tani Berdikari merupakan salah satu kelompok atau organisasi masyarakat di Kelurahan Landasan Ulin Utara Kecamatan Liang Anggang Kota Banjarbaru, yang bergerak di bidang pertanian, yang selama ini melakukan aktivitas pertanian dengan menekankan konsep mencintai alam dan keberlanjutan. Penelitian ini mengungkapkan keberadaan dan strategi-strategi yang dilakukan oleh kelompok tani Berdikari di Kota Banjarbaru ini, yang merupakan salah satu langkah nyata dalam upaya mengurangi kerusakan lingkungan yang diakibatkan berbagai macam hal. Tujuan penelitian ini untuk menggali strategi-strategi yang dilakukan dalam bertani dengan konsep mencintai alam dan berkelanjutan.

\section{Metode}

Penelitian ini menggunakan pendekatan kualitatif. Metode penelitian yang digunakan dalam penelitian ini ialah studi kasus. Jumlah Informan dalam penelitian berjumlah lima orang yang merupakan bagian dari struktur dan anggota kelompok Tani Berdikari. Penelitian ini menitikberatkan pada strategi yang digunakan oleh kelompok Tani Berdirkari di Kota Banjarbaru dalam memperkuat kewarganegaraan ekologis. Penentuan subjek penelitian menggunakan teknik purposive sampling. Pengumpulan data dilakukan melalui wawancara mendalam dengan para petani yang tergabung di dalam Kelompok Tani Berdikari, dan melalui observasi langsung melihat seperti apa petani dalam bertani. Data penelitian dianalisis dengan teknik analisis kualitatif model interaktif. Kegiatan yang dilakukan dalam analisis data yaitu reduksi data, klasifikasi data, penyajian data, dan penarikan kesimpulan.

\section{Hasil dan pembahasan}

Kelompok Tani Berdikari merupakan sebuah organisasi atau kelompok sosial yang bergerak serta fokus beraktivitas di bidang pertanian. Jumlah anggota yang ada di dalam kelompok ini hanya berjumlah 20 orang, yang terdiri dari masyarakat yang tinggal di Kelurahan Landasan Ulin Utara Kota Banjarbaru. Dalam rangka menjalankan berbagai program yang ada mereka memiliki beberapa strategi-strategi dalam menjalankan program-program pertanian yang sudah mereka implementasikan.

Kelompok Tani Berdikari selalu menekankan konsep aman, selamat, dan sehat dalam menjalani kehidupan serta mengolah hasil taninya dan menjaga lingkungan sekitar. Konsep aman merupakan bentuk utama dari kewajiban dalam menjaga lingkungan alam sekitar dengan melakukan pengolahan alam tanpa adanya ekploitasi lingkungan yang berlebihan serta mampu memberikan stabilitas terhadap wilayah tersebut.

Dengan konsep aman ini, yang merupakan gabungan dari konsep ekonomi berkelanjutan, sosial berkelanjutan, dan keberlanjutan lingkungan atau ekologi dengan membuat warga sekitar dan anggota kelompok tani melaksanakan konsep ini mampu memberikan kesejahteraan lingkungan, ekonomi dan sosial terhadap daerah tersebut.

Konsep aman, jika kita kontekstualisasikan dengan apa yang ada di dalam kajian Dash (2014, hal. 37) bahwa kewarganegaraan ekologis berisi nilai-nilai moral yang memandu perilaku individu terhadap lingkungan dan pilihan untuk hidup damai dan bersahabat dengan bumi. Dari teori di atas berarti konsep aman merupakan salah satu pilihan hidup damai dalam bersahabat dengan lingkungan bisa dilakukan dengan mengimplementasikan konsep aman dalam mengelola dan mengolah lingkungan.

Hal itu, juga selaras dengan apa yang dikemukan oleh Fahlevi, et al (2021, hal. 243) bahwa dalam mengelola lingkungan harus melihat 
keadaaan lingkungan sekitar. Artinya lingkungan sekitar merupakan prioritas utama lingkungan yang harus dijaga. Di dalam konsep aman ini berarti, strategi yang digunakan oleh Kelompok Tani Berdikari bertujuan agar lingkungan sekitar yang mereka kelola dan olah tetap aman dari kerusakan lingkungan yang ada. Ada korelasi yang kuat antara kebersihan lingkungan sekitar dengan keamanan lingkungan, suatu sistem kebersihan dan keamanan lingkungan yang lebih baik dan teratur yang dapat membuat suatu lokasi lebih bersih dan aman. (Iskandar, 2018, hal. 82).

Konsep selamat yang diterapkan oleh Kelompok Tani Berdikari ini merupakan dari rasa akan keinginan dari warganya dan Kelompok Tani Berdikari terhadap lingkungan sekitar agar terhindar dari bahaya, malapetaka, dan bencana. Konsep selamat ini adalah konsep yang simple dari konsep pertanian organik yang merupakan sistem produksi pertanian yang menghindari berbagai bahan kimia dalam melaksanakan pertanian.

Dengan menggunakan konsep selamat, maka para petani pun menggunakan pertanian organik merupakan sistem manajemen produksi terpadu yang menghindari penggunaan pupuk buatan, pestisida dan hasil rekayasa genetik, menekan pencemaran udara, tanah, dan air. Konsep ini ada relevansinya dengan faktor kerusakan alam selama ini, disebabkan karena perilaku warga masyarakat yang belum sepenuhnya sadar akan pengelolaan lingkungan. Konsep Kewarganegaraan Ekologis mensyaratkan pengetahuan, partisipasi dalam pengelolaan lingkungan, sikap peduli terhadap lingkungan (Mariyani, 2017, hal. 11).

Di sisi lain, pertanian organik meningkatkan produktivitas di antara flora, fauna dan manusia. Penggunaan masukan di luar pertanian yang menyebabkan degradasi sumber daya alam tidak dapat dikategorikan sebagai pertanian organik. Sebailknya, sistem pertanian yang tidak menggunakan masukan dari luar, namun mengikuti aturan pertanian organik dapat masuk dalam kelompok pertanian organik, meskipun agro-ekosistemnya tidak mendapat sertifikasi organik. Hal ini lah konsep selamat menjadi pillar bagi pertanian organik karena Segala yang ada di alam adalah berguna dan memiliki fungsi, saling melengkapi, melayani dan menghidupi untuk semua. Dalam alam ada keragaman hayati dan keseimbangan ekologi. (Mayrowani, 2019, hal. 95).

Konsep sehat dalam pandangan Kelompok Tani Berdikari memiliki keselarasan dengan konsep pertanian sehat yang memprioritaskan pada penggunaan bahan-bahan alami yang ramah lingkungan, mudah dan murah namun tetap menjaga produktivitas dan kualitas hasil pertanian. Konsep sehat ini membuat para anggota Kelompok Tani Berdikari menjadi tidak ketergantungan terhadap pupuk organik atau bahan kimia yang bisa merusak alam. Petani pun mampu menjaga kesehatan dan kesuburan lingkungan, karena tidak menggunakan bahan kimia maka para petani mulai berkreasi dan berinovasi dalam mengatasi berbagai ancaman yang datang. Akibat rendahnya penggunaan bahan-bahan kimia menyebabkan terjaganya kelestrian alam dan keanekaragaman hayati pada ekosistem pertanian di Kelurahan Landasan Ulin Utara Kota Banjarbaru.

Hal ini merupakan wujud dari tingginya kepedulian Kelompok Tani Berdikari dalam menjaga, mengelola dan merawat lingkungan sekitarnya. Dalam pengelolan lingkungan sangat ditekankan sekali aspek kesehatan lingkungan. Karena hal ini sangat berhubungan dengan tingkat kualitas serta berdampak ke pada makhluk hidup yang ada di sekitarnya. Artinya semakin bagus kualitas lingkungannya maka akan semakin baik pula makluk hidup yang ada di sekitarnya. Serta sebaliknya semakin buruk tingkat kesehatan lingkungannya maka semakin buruk juga kondisi makhluk hidup yang di sekitarnya. (Agyeman \& Evans 2006, hal. 198).

Dalam konsep kewarganegaraan ekologis sangat menekankan nilai moral dalam proses mengelola ekosistem lingkungan untuk kepentingan bersama. Sehingga dalam proses bertani yang merupakan salah satu cara Kelompok Tani Berdikari untuk mengelola lingkungan atau hasil taninya dengan menekanakan konsep aman, selamat dan sehat merupakan refleksi nilai-nilai moral yang ada di dalam konsep kewarganegaraan ekologis.

Selain itu, wujud strategi lain yang sudah dilakukan oleh Kelompok Tani Berdikari di Kota Banjarbaru dalam penguatan kewarganegaraan ekologis ialah melakukan kerja sama dengan stakeholder, seperti dinas pertanian dan peternakan Kota Banjarbaru, dengan hal tersebut maka mampu membuat Kelompok Tani Berdikari untuk mendapatkan berbagai bibit dan bahanbahan alami dalam melaksanakan pertanian yang sehat. Serta mendapatkan informasi-informasi dan materi penyuluhan yang penting terkait dengan cara pengelolaan lahan pertanian yang ramah lingkungan, bibit unggul dan bahan-bahan atau perlengkapan pertanian yang alami dan bekelanjutan. 


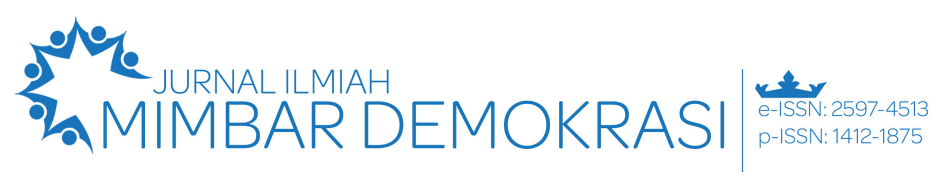

Vol. 21 No. 1 Tahun 2021 | Hal. 35 - 41

Dengan melakukan kerja sama dengan stakeholder Kelompok Tani Berdikari mendapatkan banyak keahlian dalam mengolah lahan, manajemen waktu dan hasil pertanian, serta mendapatkan pengetahuan, dan keterampilan petani dalam menjadi penunjang utama mengolah lahan. Khusus dalam masalah manajemen hasil dalam aspek biaya untuk mengirimkan barang hasil pertanian ke pasar maupun tempat lain relatif lebih murah karena dekat dengan pasar dan konsumen.

Strategi yang dilakukan oleh kelompok sosial masyarakat, seperti LSM dan NGO melakukan kerjasama dengan Pemerintah Daerah (stakeholder) yang dilakukan secara terrpadu biasanya dilakukan dengan menyelenggarakan dialog, sosialisasi, dan pelatihan. Dialog interaktif, sosialisasi, dan pelatihan dilakukan dengan misi mengenalkan serta melatih kepedulian masyarakat untuk ambil bagian dalam program pembangunan lingkungan hidup (ekologi). (Nugroho, 2017, hal. 25). Program kerja sama dengan stakeholder tersebut bertujuan memberikan pengetahuan ke pada masyarakat mengenai pentingnya kedudukan mereka dalam menjaga dan merawat lingkungan di sekitarnya. Sehingga dengan program tersebut yang berisi kegiatan dialog, pelatihan, dan sosialisasi masyarakat sadar serta ikut serta dalam program tersebut.

Bukan berarti tanpa hambatan, para
petani yang tergabung tani dalam mengimplementasikan strategi-strategi tersebut, yakni hambatan yang datang dari mengelola dan menjaga lingkungan dari kelompok tani adalah dari faktor alam dan ekonomi. Dalam faktor alam adalah biasanya munculnya hama dan wabah penyakit yang menyerang tanaman, mengakibatkan banyak tanaman yang terdampak dan mengalami kerusakan yang cukup besar sampai pernah mengalami gagal panen. Salah satu hama yang memberi kerusakan adalah hama wareng, akibat hama wareng banyak padi yang mengalami kerusakan yang besar dan bahkan mengalami gagal panen.

Adapun hambatan yang disebabkan oleh faktor ekonomi adalah turunnya harga hasil pertanian, penyebab turunnya harga hasil pertanian yaitu: masalah penggudangan tidak semua petani memiliki akses untuk penggudangan dan jika memiliki pun banyak yang kurang berkualitas sehingga produk akan mudah rusak. Kurangnya fasilitas penggudangan akan menyebabkan petani terpaksa langsung memasarkan produk pertaniannya. Sama halnya dengan sifat musiman, jika sistem penggudangan kurang maka pasokan akan melimpah dan harga produk akan menurun.

Serta masalah distribusi produk pertanian sering menjadi masalah karena masih adanya kecenderungan sifat kapitalisme di dalam proses distribusinya. Hal ini akan menyebabkan adanya kelangkaan produk pada suatu daerah yang nantinya dapat memicu kenaikan harga. Sebaliknya, sifat kapitalisme ini juga dapat menurunkan harga di daerah tertentu.

Selain itu, dalam perspektif Dobson (2007, hal. 283) faktor perilaku juga merupakan faktor dominan yang menjadi salah satu hambatan. Seperti perilaku yang mementingkan diri sendiri, tidak mementingkan untuk kepentingan bersama seperti menjaga lingkungan. Masalah lingkungan merupakan masalah kewarganegaraan yang selalu menjadi masalah mengenai keseimbangan antara hak dan tanggung jawab, partisipasi serta manusia memanfaatkan lingkungan untuk keberlanjutan hidup, namun tidak jarang sering melupakan tanggung jawab sebagai warga negara dalam menjaga dan melestarikan pelestarian lingkungan.

Tingkat partisipasi masyarakat yang kurang stabil juga merupakan salah satu faktor penghambat. Maka dari itu, sangat diperlukan sekali sinergi antara seluruh masyarakat sangat diperlukan sekali sebagai upaya pelestarian lingkungan yang ada di sekitar tempat tinggalnya. Faktor penghambat lain dalam rangka penguatan kewarganegaraan ekologis yakni kurangnya persiapan dan pendampingan oleh dinas-dinas terkait yang berhubungan dengan lingkungan.

\section{Simpulan}

Wujud dari strategi penguatan kewarganegaraan ekologis yang dilakukan oleh Kelompok Tani Berdikari Kota Banjarbaru ialah dengan menekankan dan mempraktikan konsep aman, selamat, dan sehat dalam menjalani kehidupan serta mengolah hasil taninya dan menjaga lingkungan sekitar. Ketiga konsep ini merupakan perwujudan komitmen para petani yang ada di dalam Kelompok Tani Berdikari dalam menjaga lingkungan secara berkelanjutan. Serta sudah mengimplementasikan konsep kewarganegaraan ekologis yang sangat menekankan nilai moral dalam proses mengelola ekosistem lingkungan untuk kepentingan bersama. Selain itu, wujud strategi lain yang sudah dilakukan oleh Kelompok Tani Berdikari di Kota Banjarbaru dalam penguatan kewarganegaraan ekologis ialah melakukan kerja sama dengan 
stakeholder, seperti dinas pertanian dan peternakan Kota Banjarbaru, dengan hal tersebut maka mampu membuat Kelompok Tani Berdikari untuk mendapatkan berbagai bibit dan bahanbahan alami dalam melaksanakan pertanian yang sehat. Hambatan- hambatan yang ditemui para petani yang tergabung di dalam Kelompok Tani Berdikari dalam mengimplementasikan strategi ini dari faktor alam dan ekonomi.

\section{Referensi}

Agyeman, J., \& Evans, B. (2006). Justice, governance, and sustainability: perspectives on environmental citizenship from North America and Europe. Environmental citizenship, 185-206.

Berkowitz, A. R., Ford, M. E., Brewer, C. A., Johnson, E. A., \& Mappin, M. J. (2005). Environmental education or advocacy: Perspectives of ecology and education in environmental education. A framework for integrating ecological literacy, civics literacy, and environmental citizenship in environmental education, 227-266.

Dash, A. (2014). 'International Review of Sociology: Revue Internationale de Sociologie: the Moral Basis of Sustainable Society: the Gandhian Concept of Ecological Citizenship', International Review of Sociology, vol. 24, no. 1. hh. 3741.

Dobson, A. (2007). Environmental citizenship: towards sustainable development. Sustainable development, 15(5), 276-285.

Dobson, S., \& Sukumar, A. (2017). Memes and civic action: Building and sustaining civic empowerment through the internet. In The Virtual and the Real in Planning and Urban Design (pp. 267-278). Routledge.

Fahlevi, R., Jannah, F., \& Sari, R. (2020). Implementasi Nilai-Nilai Karakter Peduli Lingkungan Sungai Berbasis Kewarganegaraan Ekologis Melalui Program Adiwiyata di Sekolah Dasar. Jurnal Moral Kemasyarakatan, 5(2), 68-74.

Fahlevi, R., \& Sari, F. J. R. (2021). Internalization of River Culture Literacy
Based on Ecological Citizenship at Adiwiyata School.

Faiz, P. M. (2016). Perlindungan Terhadap Lingkungan Dalam Perspektif Konstitusi (Environmental Protection in Constitutional Perspective). Jurnal Konstitusi, 13(4), 766787.

Gusmadi, S. (2018). keterlibatan warga Negara (civic engagement) dalam penguatan karakter peduli lingkungan. Mawa'izh: Jurnal Dakwah Dan Pengembangan Sosial Kemanusiaan, 9(1), 105-117.

Gusmadi, S., \& Samsuri, S. (2020). Gerakan Kewarganegaraan Ekologis Sebagai Upaya Pembentukan Karakter Peduli Lingkungan. Jurnal Ilmiah Pendidikan Pancasila Dan Kewarganegaraan, 4(2), 381-391.

Isin, E. F., \& Turner, B. S. (Eds.). (2002). Handbook of citizenship studies. Sage.

Iskandar, A. A. (2018). Pentingnya Memelihara Kebersihan Dan Keamanan Lingkungan Secarapartisipatif Demi Meningkatkan Gotong Royong Dan Kualitas Hidup Warga. Jurnal Ilmiah Pena: Sains dan Ilmu Pendidikan, 10(1), 79-84.

Jannah, R. (2018). Menciptakan Kewarganegaraan Ekologis di Era Digital Melalui Kampoeng Recycle Jember. Journal of Urban Sociology, 1(2), 14-26.

Mariyani, M. (2017). Strategi Pembentukan Kewarganegaraan Ekologis. Prosiding Konferensi Nasional Kewarganegaraan III. Universitas Ahmad Dahlan, Yogyakarta.

Mayrowani, H. (2019). Pengembangan pertanian organik di Indonesia. Forum Penelitian Agro Ekonomi, Volume 30 No. 2, Desember 2012 : 91 - 108 .

Nugroho, D. A. (2017). Penguatan Ecological Citizenship melalui penerapan Pendidikan Pancasila dan kewarganegaraan berbasis masyarakat. Prosiding Konferensi Nasional Kewarganegaraan III. Universitas Ahmad Dahlan, Yogyakarta. 


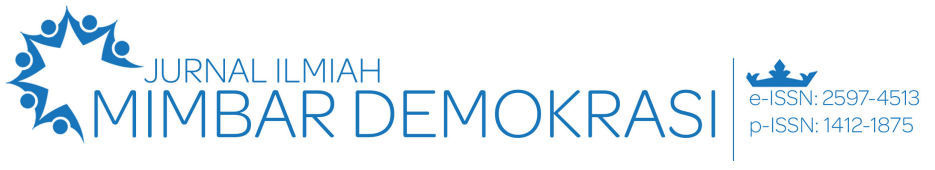

Vol. 21 No. 1 Tahun 2021 | Hal. 35 - 41

Nurmayanti, I. (2017). Strategi Yayasan Mangrove Center Tuban dalam Mengembangkan Ecological Citizenship pada Masyarakat Tuban. Kajian Moral dan Kewarganegaraan, 5(02).

Mustikarini, I. D., \& Feriandi, Y. A. (2020). Konfigurasi Pendidikan Kewarganegaraan Ekologi Perspektif sosio-kultural (Gagasan Pembentukan Pendidikan Kewarganegaraan Kontium Maksimal di Indonesia). JPK (Jurnal Pancasila dan Kewarganegaraan), 5(2), 54-64.

Prasetiyo, W. H., \& Budimansyah, D. (2016). Warga negara dan ekologi: Studi kasus pengembangan warga negara peduli lingkungan dalam komunitas bandung berkebun. Jurnal pendidikan humaniora, 4(4), 177-186.

Sari, S. C. W., Samsuri, S., \& Wahidin, D. (2020). Penguatan Kewarganegaraan Ekologis Untuk Mewujudkan Ketahanan Lingkungan (Studi di Kampung Gambiran, Kelurahan Pandeyan, Kecamatan Umbulharjo, Kota Yogyakarta, Daerah Istimewa Yogyakarta). Jurnal Ketahanan Nasional, 26(1), 40-54.

Syahri, M. (2013). Bentuk-Bentuk Partisipasi Warga Negara dalam Pelestarian Lingkungan Hidup Berdasarkan Konsep Green Moral di Kabupaten Blitar. Jurnal Penelitian Pendidikan, 13 (2), 119-134. 